\title{
ASSESSMENT OF VARIOUS PARAMETERS OF DENTAL ANXIETY AMONG NURSING STUDENTS IN RURAL AND URBAN AREA OF BAREILLY CITY INDIA -A CROSS SECTIONAL SURVEY
}

\author{
Yadav $K^{1}$, Lakshminaryan $N^{2}$
}

${ }^{1}$ Department of Public Health and Community Dentistry, Nepal Medical College Teaching Hospital, Gokarneshwor-8, Kathmandu Nepal, ${ }^{2}$ Department of Public Health and Community Dentistry, Bapuji Dental College and Hospital Davangere, Karnataka, India.

\begin{abstract}
To assess the various parameters of dental anxiety among nursing students in rural and urban area of Bareilly city India. A cross-sectional survey was conducted among nursing students aged 18 to 25 years in Bareilly city of Uttar Pradesh State in India. Dental anxiety was measured using Modified Dental Anxiety Scale (MDAS). It consists of three six-item scales that also use the Likert format. The data obtained were analysed using Analysis of variance (ANOVA). The study group individuals in majority were slightly anxious (59.4\% and $47.5 \%)$ when questioned about their feelings on visit to dentist and sitting in dentist's waiting area, while they would feel extremely anxious (29.9\%) if they were to receive local anesthesia respectively. The conclusion drawn from the present study was that all are "slightly anxious" as compare to others.
\end{abstract}

\section{KEYWORDS}

Corah's dental anxiety, cross-sectional survey, dental anxiety, modified dental anxiety

\section{CORRESPONDING AUTHOR}

Dr. Karnika Yadav,

Lecturer,

Department of Public Health and Community Dentistry,

Nepal Medical College Teaching Hospital,

Attarkhel, Gokarneshwor-8, Kathmandu, Nepal.

Email: karnikayadav63@gmail.com 


\section{INTRODUCTION}

Oral health is critically dependent on behavior like - attendance at the dentist, dietary behavior, cessation of smoke and self -care routines. Social and behavioral sciences provide a critical insight into the determinants of behavior and how these can be modified. ${ }^{1}$ People with dental fear and anxiety are known to avoid regular dental care, causing further deterioration of their oral health status. ${ }^{2}$ Thus they are more likely to utilize emergency dental services once they had dental pain and have a negative dental experience. ${ }^{3}$

Dental anxiety is a major complication for both patient and dentist. ${ }^{4}$ Anxiety is defined as apprehension of danger and dread, accompanied by restlessness, tension, tachycardia and dyspnea unattached to a clear unidentifiable stimulus. ${ }^{5}$ This apprehension leads patients to postpone or cancel dental visits or avoid treatment entirely. It is confirmed that anxious patients have more decayed, missing and less filled teeth in comparison to non anxious patients. ${ }^{6}$ Dental anxiety is a multidimensional complex phenomenon, and never a single variable can account exclusively for development of anxiety.

There are a number of factors that have consistently been linked with a greater incidence of dental anxiety which includes personality characteristics, fear of pain, past traumatic dental experiences, particularly in childhood (conditioning experiences), the influence of dentally anxious family members or peers which elicit fear in a person (vicarious learning), and blood injury fears. ${ }^{7}$ Anxiety and fear towards dental treatment are common problems frequently experienced by patients worldwide. ${ }^{8}$ Dental anxiety is a multidimensional psychological construct which needs to be measured. Modified Dental Anxiety Scale (MDAS) is the most commonly reported tool to measure the dental anxiety. ${ }^{9}$ Hence, the present study will be conducted with an aim to assess the various parameters of dental anxiety among nursing students in rural and urban area of Bareilly City.

\section{MATERIALS AND METHODS}

A cross-sectional survey was conducted among nursing students aged 18-25 years in 2016 in Bareilly. Ethical clearance was obtained from Ethical Review Board of Institute of Dental Sciences, Bareilly. Random selection was done by using the college roster as a sampling frame. Voluntary informed consent was obtained from all the selected subjects after clearly explaining the purpose and procedures of the study.

The sample size estimation for this study was done based on prevalence of earlier study. ${ }^{10} \mathrm{~A}$ total of 628 subjects (male and female) aged between 18-25 years of age were randomly selected for the study. The questionnaire was divided into two parts, the first part contains the demographic profile, which includes age, sex, occupation and residence in nursing course. The other group included the assessment of dental anxiety which was captured by the Modified dental anxiety scale (MDAS). The questionnaire was translated into local language (Hindi) and prevalidated.

Participants were allowed to choose from five responses (scored 1 to 5), ranging from 'not anxious' to 'extremely anxious'. People with total values between 5 to 18 were categorized in the low dental anxiety group and those with total values between 19 and 25 in the high anxiety group. Statistical comparisons were done using Analysis of Variance. ${ }^{11}$

\section{RESULTS}

Out of 628 subjects a majority $412(65.4 \%)$ of them belonged to below 20 years, $191(30.6 \%)$ subjects were between 21 - 25 years and 23 (3.7\%) subjects were between 26-30 years and only $2(0.3 \%)$ subjects were above 31 years (Table 1 ).

Table 1: Age wise distribution of subjects

\begin{tabular}{|lcc|} 
Age (Years) & $\mathbf{n}$ & $\mathbf{\%}$ \\
$<20$ & 412 & 65.4 \\
$21-25$ & 191 & 30.6 \\
$26-30$ & 23 & 3.7 \\
$>31$ & 2 & 0.3 \\
Total & $\mathbf{6 2 8}$ & $\mathbf{1 0 0}$ \\
\hline
\end{tabular}

Out of 628 subjects a majority $534(84.8 \%)$ of them were females and $94(15.2 \%)$ subjects were males (Table 2).

Table 2: Sexwise distribution of subjects

\begin{tabular}{|lcc|} 
Gender & $\mathbf{n}$ & $\mathbf{\%}$ \\
Female & 534 & 84.8 \\
Male & 94 & 15.2 \\
Total & $\mathbf{6 2 8}$ & $\mathbf{1 0 0 . 0}$ \\
\hline
\end{tabular}

Out of 628 subjects a majority $318(50.8 \%)$ of subjects belonged to urban and 310 (49.2\%) subjects belonged to rural areas (Table 3).

Table 3: Residencewise distribution of subjects

\begin{tabular}{lcc|} 
Residence & $\mathbf{n}$ & $\mathbf{\%}$ \\
Urban & 318 & 50.8 \\
Rural & 310 & 49.2 \\
Total & $\mathbf{6 2 8}$ & $\mathbf{1 0 0 . 0}$ \\
\hline
\end{tabular}




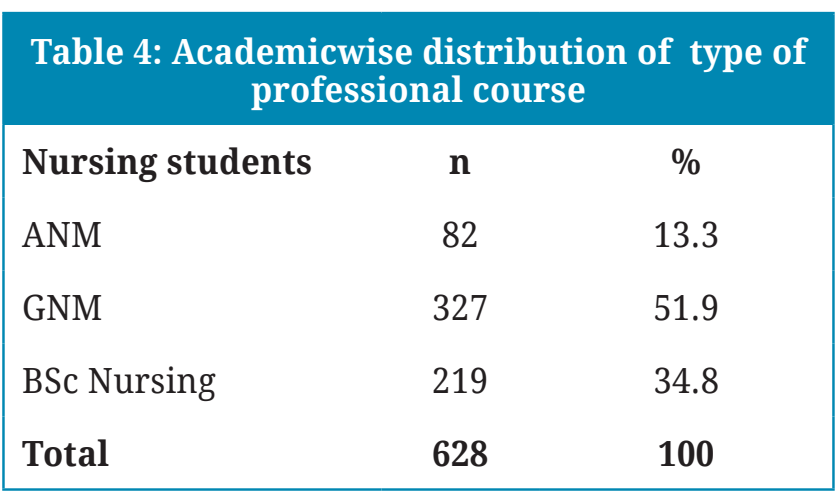

A majority 327 (51.9\%) were students in General Nursing Midwifery (GNM) course, 219 (34.8\%) subjects were students in Bachelor of Science (BSc) in Nursing and $82(13.3 \%)$ subjects were students in Auxiliary Nurse Midwifery (ANM) course (Table 4).

As shown in Table 5, distribution of subjects based on answers given for different questions were as follows:

From the response obtained from question 1, maximum of 374 (59.4\%) were found to be slightly anxious and only 24 (3.8\%) were extremely anxious. Around 90 (14.3), 88 (14.1\%) and 52 (8.4\%) were found to be not anxious, fairly anxious and very anxious respectively.

According to answers for question 2, 299 (47.5\%) were found to be slightly anxious and only $53(8.4 \%)$ were not anxious. Around 124 (19.7\%), 96 (15.6\%) and $56(8.9 \%)$ were found to be fairly anxious, very anxious and extremely anxious, respectively.

From the response obtained from question 3, only $189(30.0 \%)$ were found to be slightly anxious and only 30 (4.8\%) were not anxious. Around 161 (25.6\%), $131(21.1 \%)$ and 117 (18.6\%) were found to be fairly anxious, very anxious and extremely anxious as far as magnitude of problem is concerned.

As for the question 4, maximum of 217 (34.8\%) were found to be slightly anxious and 59 (9.4\%) were extremely anxious. Around 128 (20.3\%), 127 (20.2\%) and 97 (15.4\%) were found to be not anxious, fairly anxious and very anxious.

From the respondents for question 5, majority of 188 (29.9\%) were found to extremely anxious and only 50 (7.9\%) were not anxious. Around 138 (22.0\%), 137 (21.7\%) and 115 (18.3\%) were found to be slightly anxious, very anxious and fairly anxious.

\section{Table 5: Distribution of subjects based on answers given for questions}

\section{Questions}

1.If you were to go to your dentist for treatment

tomorrow, how would you feel?

2.If you were sitting in the waiting room (waiting for treatment), how would you feel?

3.If you were about to have a tooth drilled, how would you feel?

4.If you were about to have your teeth scaled and polished, how would you feel?

5.If you were about to have a local anaesthetic injection in your gum, about an upper back tooth, how would you feel?

$\begin{array}{ccccc}\begin{array}{c}\text { Not } \\ \text { Anxious } \\ \mathbf{n}(\%)\end{array} & \begin{array}{c}\text { Slightly } \\ \text { Anxious } \\ \mathbf{n}(\%)\end{array} & \begin{array}{c}\text { Fairly } \\ \text { Anxious } \\ \mathbf{n}(\%)\end{array} & \begin{array}{c}\text { Very } \\ \text { Anxious } \\ \mathbf{n}(\%)\end{array} & \begin{array}{c}\text { Extremely } \\ \text { Anxious } \\ \mathbf{n}(\%)\end{array} \\ 90(14.3) & 374(59.4) & 88(14.1) & 52(8.4) & 24(3.8) \\ 53(8.4) & 299(47.5) & 124(19.7) & 96(15.6) & 56(8.9)\end{array}$

$30(4.8) \quad 189(30.0) \quad 161(25.6) \quad 131(21.1) \quad 117(18.6)$

$128(20.3) \quad 217(34.8) \quad 127(20.2) \quad 97(15.4) \quad 59(9.4)$

$50(7.9) \quad 138(22) \quad 115(18.3) \quad 137(21.7) \quad 188(29.9)$ 


\section{DISCUSSION}

In recent times the everyday clinical practice of dentistry has benefited from major advancements in techniques, technologies and materials, as well as in infection control procedures. Despite these gains, anxiety related to the dental environment is a problem suffered by many patients worldwide. It remains a significant challenge in providing dental care. Anxiety is an emotional state that helps normal individuals defend themselves against a variety of threats and dental anxiety refers to patient's specific response towards dental problem- associated stress. The current study is a cross-sectional survey and it is done in a systemic randomly selected sample of 628 nursing students aged between 18-31 years in Bareilly City. In the present study Modified Corah's Dental Anxiety Scale has been used which has good psychometric properties. However it has been criticized as being brief. This can provide meaningful measures only to extremely high or extremely low dental anxiety; moreover it does not include any reference to local anesthetic injections, a major focus of anxiety for many.

In the present study 628 subjects the data regarding age, sex and residence distribution clearly showed that there are more or less equal number of nursing students from urban and rural areas and maximum students of them belonged to age below 20 years and also females are more in number than males. The literature showed that women have a lower tolerance to pain and generally reports higher levels of anxiety. Similar results were observed in the present study. This reports a significant difference in the anxiety of males and females. ${ }^{8,12,13,14,15}$

In case with the distribution of nursing course in the study subjects, the results showed that, majority of the subjects were from General Nursing
Midwifery students when compared to Bachelor of Science and Auxiliary Nurse Midwifery course. The possible reasons might be that there is a relatively lack of awareness about dental treatment or they are more apprehensive towards the procedurated treatment. The result of this study could not be compared with the other studies because none of the studies reported in the literature have measured this parameter.

When the subjects were asked how they felt if their treatment were post-poned for the next day, they felt slightly anxious. The possible reason could be that they were not having any past dental experience. Majority of the subjects were slightly anxious when being asked how they felt sitting in the waiting room while for treatment. This might be due to the reason that they were unaware of dental treatments and procedures. The division of subjects according to the answer given for question no. 3 showed that, majority of the subjects were slightly anxious when being asked on how they felt if they were about to have a tooth drilled. When asked how they felt if they had their teeth scaled or polished majority of them were slightly anxious. The reason for this could be that majority of them were not aware of the dental treatment. However, when asked regarding the injection of local anesthetic majority of the subjects were extremely anxious. This may be due to fear from injection as well as due to the fact the whole procedure is under the control of the dentist.

In conclusion, the findings of this study suggest that prevalence of dental anxiety was high among the study subjects this will reflect the level of awareness of dental anxiety among the subjects. Further studies are needed to address the dental anxiety levels in different populations, which will help dental care providers to better manage their patients in the future.

\section{REFERENCES}

1. Freeman R. Barriers to accessing and accepting dental care. Brit Dent J 1999; 187: 81-4.

2. Hattiwala S, Acharya S, Patil S. Personality and psychological factors: Effects on dental beliefs. J Indian Soc Pedod Prev Dent 2015; 33: 88-92.

3. Abtahi M.S.M, Mohammadi G. The prevalence of dental anxiety and fear inpatients referred to Isfahan Dental School Iran. J Dent Res (Isfahan) 2015; 12: 248-53.

4. Berggren U, Carlsson S.G. Psychometric Measures of Dental Fear. Community Dent Oral Epidemiol 1984; 12:319-24.

5. Malvania EA, Ajithkrishnan CG.Prevalence and socio-demographic correlatesof dental anxiety

among a group of adult patients attending a Dental Institutionin Vadodara city, Gujarat, India. Indian J Dent Res 2011; 22: 195-9.

6. Nigam AG, Marwah N, Goenka P. Correlation of general anxiety and dental anxiety in children aged 3 to 5 years: A clinical survey. J Int Oral Health 2013; 5: 18-24.

7. Appukuttan DP, Tadepalli A, Cholan KP. Prevalence of dental anxiety among patients attending a dental educational institution in Chennai, India- A Questionnaire Based Study. Oral Health Dent Manag 2013; 12: 289-94.

8. Thomson WM, Broadbent JM, Locker D. Trajectories of dental anxiety in a birth cohort. Community Dent Oral Epidemiol 2009; 37: 209-19. 
9. Corah NL. Development of a dental anxiety scale. J Dent Res 1969; 48: 596-10.

10. Jekel JF, Katz DL, Joann G. Epidemiology, Biostatistics and Preventive Medicine-Third edition. Elmore-Saunders Elsevier 2007: 216-9.

11. Acharya S, Sangam DK. Dental Anxiety and its Relationship with self perceived Health Locus of Control among Indian dental Student. Oral Health Prev Dent 2010; 8: 9-14.

12. Moore R, Birn H, Kirkegaard E, Brødsgaard I, Scheutz F. Prevalence andcharacteristics of dental anxiety in Danish adults. Community Dent Oral Epidemiol 1993; 21: 292-6.
13. Sghaireen MG, Zwiri MA, Alzoubi IA. Anxiety due to Dental Treatment and Procedures among University Students and Its Correlation with Their Gender and Field of Study. Int'l J Dentistr 2013 Article ID 647436, https://doi. org/10.1155/2013/647436.

14. Sohn W, Ismail AI. Regular dental visits and dental anxiety in an adult dentate population. $J$ Am Dent Assoc 2005; 136: 58-66. 